\title{
KONSUMSI PANGAN SUMBER ZAT BESI DAN ASAM FOLAT DENGAN ANEMIA PADA IBU HAMIL DI PUSKESMAS TAWAELI
}

\author{
Suastira $^{1 \mathrm{~K}}$, Sumiaty ${ }^{2}$, Ansar ${ }^{1}$ \\ ${ }^{1}$ Prodi DIII Gizi Jurusan Gizi Poltekkes Kemenkes Palu \\ ${ }^{2}$ Prodi DIII Kebidanan Palu Jurusan Kebidanan Poltekkes Kemenkes Palu \\ ${ }^{3}$ Prodi DIII Gizi Jurusan Gizi Poltekkes Kemenkes Palu \\ email Penulis Korespondensi ${ }^{(\mathrm{K})}$ : suastirapoltekkespalu@gmail.com
}

\begin{abstract}
Anemia is a condition where the hemoglobin level in the blood is below normal. Anemia is directly caused by daily food intake that contains less iron and folic acid. Data from the Basic Health Research conducted in 2013 showed that the proportion of pregnant women who were anemic in Indonesia reached $37.1 \%$, in Central Sulawesi anemia in pregnant women reached $24.42 \%$, then for the Palu city it was found in the Tawaeli Health Center reaching $58,7 \%$. The purpose of this study was to determine the relationship between food consumption and folic acid with the incidence of anemia in pregnant women in the Tawaeli Health Center Area. This type of research is analytic observational using cross sectional. Sampling is done by visiting the respondent's place directly or door to door with 40 people. Data collection was done directly, using a food frequency questionnaire (FFQ) and to find out anemia in pregnant women using $\mathrm{Hb}$ meter (Diaspect). The results showed that the percentage of anemia anemia was higher in pregnant women who rarely discussed iron food $(56.7 \%)$ with the results of statistical tests showing $\mathrm{p}$ value $=0.02(\mathrm{p}<0.05)$ and folic acid $(52.6 \%)$ with the results of statistical tests showing a $p$ value of $0.04(p<0.05)$. The results showed an association between iron food and folic acid with the incidence of anemia in pregnant women.
\end{abstract}

Keywords: Iron, folic acid, pregnant women, anemia

\section{PENDAHULUAN}

\section{Latar Belakang}

Ibu hamil merupakan salah satu kelompok rawan kekurangan gizi, karena terjadi peningkatan kebutuhan gizi untuk memenuhi kebutuhan ibu dan janin yang dikandung. Ibu hamil merupakan kelompok sasaran yang sangat perlu mendapat perhatian khusus. Hal ini didasarkan pada masalah gizi yang dijumpai serta dampak negatif yang ditimbulkan karena status gizi ibu hamil, tidak hanya berpengaruh pada dirinya sendiri tetapi juga pada perkembangan janinnya yang akan dilahirkannya ${ }^{(1)}$. Salah satu masalah gizi yang banyak terjadi pada ibu hamil adalah anemia, yang merupakan masalah gizi mikro terbesar dan tersulit diatasi di seluruh dunia, World Health Organization (WHO) melaporkan prevalensi anemia pada ibu hamil yang tertinggi adalah Asia Tenggara (75\%), kemudian Mediterania Timur (55\%), Afrika (50\%), serta wilayah Pasifik Barat, 40\% Amerika dan Karibia ${ }^{(2)}$. Data hasil Riset Kesehatan Dasar yang dilakukan pada tahun 2013. menunjukkan bahwa proporsi Ibu 
Hamil yang mengalami anemia di Indonesia mencapai 37,1\%. Untuk kadar $\mathrm{Hb}$ di bawah batas normal, ditemukan proporsi yang hampir sama antara kawasan perkotaan $36,4 \%$ dan pedesaan $37,8 \%{ }^{(3)}$.

Proporsi ibu hamil anemia di Sulawesi Tengah khususnya Kota Palu pada tahun 2016 menunjukkan bahwa anemia pada ibu hamil mencapai $24,42 \%$, sedangkan untuk proporsi tertinggi dari 12 puskesmas yang berada di Kota Palu adalah Puskesmas Tawaeli mencapai $58,7 \%{ }^{(4)}$. Ibu hamil yang mengalami anemia dapat berisiko meningkatkan mortalitas dan morbiditas pada ibu dan bayi. Ibu hamil yang anemia dapat berisiko mengalami perdarahan postpartum, hal ini didukung oleh penelitian Sumiaty,dkk yang menunjukkan bahwa ada hubungan antara anemia dengan kejadian perdarahan postpartum, ibu yang anemia memiliki risiko 28 kali mengalami perdarahan postpartum ${ }^{(5)}$.

Konsumsi makanan sehari-hari yang kurang mengandung zat besi dapat menjadi penyebab langsung terjadinya anemia, selain faktor infeksi. Anemia terjadi pula karena peningkatan kebutuhan pada tubuh seseorang seperti pada saat menstruasi, kehamilan, melahirkan, sementara zat besi yang masuk sedikit. Secara umum, konsumsi makanan berkaitan erat dengan status gizi. Bila makanan yang dikonsumsi mempunyai nilai gizi yang baik, maka status gizi juga baik, sebaliknya bila makanan yang dikonsumsi kurang nilai gizinya, maka dapat menyebabkan kekurangan gizi. Selain itu, perilaku konsumsi makanan seseorang dipengaruhi oleh faktor instrinsik, yaitu faktor-faktor yang berasal dari diri seseorang seperti usia, jenis kelamin, dan keyakinan, serta faktor ekstrinsik, yaitu faktorfaktor yang berasal dari luar diri seseorang seperti tingkat ekonomi, pendidikan, tempat tinggal, lingkungan social, dan kebudayaan ${ }^{(6)}$.

Hasil penelitian yang dilakukan oleh Wulandari tahun $2010^{(7)}$ menunjukkan juga bahwa ada hubungan antara konsumsi makanan sumber zat besi dengan kejadian anemia pada ibu hamil Trimester III di Wilayah kerja Puskesmas Panti Jember. Hasil penelitian lain yang dilakukan di Wilayah kerja Puskesmas Sunggal menunjukkan bahwa ada hubungan yang bermakna antara kecukupan asam folat dengan kadar $\mathrm{Hb}$ pada ibu hamil, ibu hamil dengan asam folat yang kurang sebesar $86,4 \%$ Anemia, Sedangkan ibu hamil dengan asam folat cukup atau baik hanya $39,3 \%$ yang mengalami anemia ${ }^{(8)}$.

Hasil survey awal diperoleh bahwa wilayah kerja Puskesmas Tawaeli merupakan daerah dengan proporsi anemia tertinggi di Kota Palu mencapai 58,7\% dan masih membatasi konsumsi makanan tertentu, sehingga perlu ada kajian secara ilmiah yang berkaitan dengan frekuensi konsumsi pangan sumber zat besi dan asam folat ${ }^{(4)}$.

\section{Tujuan}

Penelitian ini bertujuan untuk menganalisis hubungan frekuensi konsumsi pangan sumber zat besi dan asam folat dengan kejadian anemia pada ibu hamil.

\section{METODE PENELITIAN}

Jenis Penelitian ini adalah observasional analitik dengan pendekatan cross sectional. Pengambilan sampel dilakukan dengan cara kunjungan langsung ketempat responden atau door to door dengan jumlah 40 orang. Pengumpulan data dilakukan secara wawancara langsung, menggunakan kuesioner food frekuensi (FFQ) serta untuk mengetahui anemia pada ibu hamil menggunakan alat $\mathrm{Hb}$ meter (Diaspect). 


\section{HASIL PENELITIAN}

\section{Hasil Analisis Karakteristik Responden}

Tabel 1

Distribusi Karakteristik ibu hamil di Wilayah Puskesmas Tawaeli, Kota Palu, Tahun 2017

\begin{tabular}{lcc}
\hline Karakteristik Responden & $\mathrm{n}$ & $\%$ \\
\hline Umur ibu & & \\
$20-29$ tahun & 28 & 70,0 \\
$30-35$ tahun & 12 & 30,0 \\
\hline Usia kehamilan & 2 & 5,0 \\
$\quad$ Trimester I & 16 & 40,0 \\
Trimester II & 22 & 55,0 \\
$\quad$ Trimester III & & \\
Wilayah tempat tinggal & 11 & 27,5 \\
Kayumalue Pajeko & 7 & 17,5 \\
Kayumalue Ngapa & 14 & 35,0 \\
Panau & 8 & 20,0 \\
Lambara & & \\
Pekerjaan & 36 & 90,0 \\
IRT & 2 & 5,0 \\
PNS & 2 & 5,0 \\
Wiraswasta & &
\end{tabular}

Pada tabel 1 analisis univariat hasil karakteristik responden penelitian ini diketahui bahwa sebagian besar ibu hamil berada pada usia 20-29 tahun (70\%), kemudian untuk usia kehamilan lebih didominasi oleh Trimester III (55\%). Distribusi ibu hamil terbanyak berdasarkan wilayah tempat tinggal berada di Kelurahan Panau (35\%). Distribusi ibu hamil berdasarkan pekerjaan sebagian besar ibu hamil (90\%) bekerja sebagai ibu rumah tangga (IRT),

Tabel 2

Distribusi Responden Berdasarkan Frekuensi Konsumsi Pangan Sumber Zat Besi, Asam Folat dan Status Hb Di Wilayah Kerja Puskesmas Tawaeli, Kec. Tawaeli, Kota Palu Tahun 2017

\begin{tabular}{lll}
\hline Variabel Penelitian & $\mathrm{n}$ & $\%$ \\
\hline Frekuensi konsumsi pangan sumber zat besi & & \\
Jarang & 30 & 75,0 \\
Sering & 10 & 25,0 \\
\hline Frekuensi konsumsi pangan sumber asam folat & 38 & 95,0 \\
Jarang & 2 & 5,0 \\
Sering & & \\
\hline Status Hb & 20 & 50,0 \\
Anemia & 20 & 50,0 \\
Tidak anemia & & \\
\hline
\end{tabular}

Hasil analisis univariat pada tabel 2 distribusi responden berdasarkan frekuensi konsumsi pangan sumber zat besi, asam folat dan status $\mathrm{Hb}$ diperoleh bahwa $75 \%$ responden jarang mengkonsumsi pangan sumber zat besi. Frekuensi konsumsi pangan sumber asam folat sangat rendah (95\%) dan proporsi ibu hamil yang mengalami anemia berkisar 50\%. Bila dilihat 
pada status $\mathrm{Hb}$ diperoleh bahwa ibu hamil yang mengalami anemia lebih banyak ditemukan pada trimester III, hal ini dapat dilihat pada tabel 3 berikut ini.

Tabel 3

Distribusi Responden Yang Mengalami Anemia Berdasarkan Trimester Kehamilan Di Wilayah Kerja Puskesmas Tawaeli, Kec. Tawaeli, Kota Palu Tahun 2017

\begin{tabular}{lcccccc}
\hline \multirow{2}{*}{$\begin{array}{l}\text { Anemia } \\
\text { berdasarkan }\end{array}$} & \multicolumn{5}{c}{ Status Hb } & \multirow{2}{*}{ Total } \\
\cline { 2 - 5 } Trimester kehamilan & \multicolumn{2}{c}{ Anemia } & \multicolumn{2}{c}{ Tidak anemia } & \\
\cline { 2 - 6 } & $\mathrm{n}$ & $\%$ & $\mathrm{~N}$ & $\%$ & $\mathrm{n}$ & $\%$ \\
\hline Trimester 1 & 1 & 50,0 & 1 & 50,0 & 2 & 100,0 \\
Trimester II & 8 & 50,0 & 8 & 50,0 & 16 & 100,0 \\
Trimester III & 11 & 50,0 & 11 & 50,0 & 22 & 100,0 \\
\hline
\end{tabular}

\section{Hasil Analisis Hubungan Antara Variabel Konsumsi Pangan Sumber Zat Besi dengan Anemia Pada Ibu Hamil}

Bila dilihat pada tabel 4 nampak bahwa responden yang sering mengkonsumsi pangan sumber zat besi cenderung akan mengalami anemia (56,7\%), sedangkan orang yang sering mengkonsumsi pangan sumber zat besi cenderung tidak mengalami anemia (70\%).

Tabel 4

Hubungan Frekuensi Konsumsi Pangan Sumber Zat Besi Dengan Anemia Pada Ibu Hamil Di Wilayah Kerja Puskesmas Tawaeli, Kec. Tawaeli, Kota Palu Tahun 2017

\begin{tabular}{|c|c|c|c|c|c|c|c|}
\hline \multirow{3}{*}{$\begin{array}{l}\text { Konsumsi } \\
\text { pangan } \\
\text { sumber zat } \\
\text { besi }\end{array}$} & \multicolumn{4}{|c|}{ Status $\mathrm{Hb}$} & \multirow{2}{*}{\multicolumn{2}{|c|}{ Total }} & \multirow{3}{*}{$\begin{array}{l}\text { P value Yate's } \\
\text { correction }\end{array}$} \\
\hline & \multicolumn{2}{|c|}{ Anemia } & \multicolumn{2}{|c|}{ Tidak anemia } & & & \\
\hline & $\mathrm{n}$ & $\%$ & $\mathrm{n}$ & $\%$ & $\mathrm{n}$ & $\%$ & \\
\hline Jarang & 17 & 56,7 & 13 & 43,3 & 30 & 100,0 & 002 \\
\hline Sering & 3 & 30,0 & 7 & 70,0 & 10 & 100,0 & \\
\hline
\end{tabular}

Hasil uji statistik dengan menggunakan Chi Square (Yate's Correction) didapatkan nilai $\mathrm{p}$ value 0,02 atau $\mathrm{p}$ value $<0,05$ yang berarti Ho ditolak yakni ada hubungan yang bermakna antara frekuensi konsumsi pangan sumber zat besi dengan kejadian anemia pada ibu hamil.

Tabel 5

Hubungan Frekuensi Konsumsi Pangan Sumber Asam Folat Dengan Anemia Pada Ibu Hamil Di Wilayah Kerja Puskesmas Tawaeli, Kec. Tawaeli, Kota Palu Tahun 2017

\begin{tabular}{cccccccc}
\hline $\begin{array}{c}\text { Konsumsi } \\
\text { pangan } \\
\text { sumber }\end{array}$ & \multicolumn{4}{c}{ Status Hb } & & Total & $\begin{array}{c}\text { P value } \\
\text { Fisher's Exact } \\
\text { Test }\end{array}$ \\
\cline { 2 - 6 } asam folat & Anemia & \multicolumn{3}{c}{ Tidak anemia } & & & \\
\cline { 2 - 7 } & $\mathrm{n}$ & $\%$ & $\mathrm{~N}$ & $\%$ & $\mathrm{n}$ & $\%$ & \\
Jarang & 20 & 52,6 & 18 & 47,4 & 38 & 100,0 & 0,04 \\
Sering & 0 & 0 & 2 & 100,0 & 2 & 100,0 & \\
\hline
\end{tabular}

Pada tabel 5 diperoleh hasil yaitu ibu hamil yang jarang mengkonsumsi pangan sumber asam folat sebagian besarnya (52,6\%) mengalami anemia, sedangkan ibu yang sering mengkonsumsi pangan sumber asam folat tidak ada yang mengalami anemia.

Hasil uji statistik dengan menggunakan Chi Square (Fisher Exact) didapatkan nilai p value 0,04 atau $p$ value $<0,05$ yang berarti Ho ditolak yang berarti ada hubungan yang bermakna 
antara frekuensi konsumsi pangan sumber asam folat dengan kejadian anemia pada ibu hamil.

\section{PEMBAHASAN}

\section{Hubungan Konsumsi Pangan Sumber Zat Besi dengan Anemia pada Ibu Hamil}

Hasil penelitian ini menunjukkan bahwa ada hubungan antara konsumsi pangan sumber zat besi dengan anemia pada ibu hamil. Ibu yang sering mengkonsumsi pangan sumber zat besi akan terhindar dari kejadian anemia. Sumber zat besi dan asam folat yang sering dikonsumsi oleh responden pada penelitian ini adalah yang bersumber dari nabati seperti tahu dan tempe. Responden sering mengkonsumsi pangan sumber zat besi dan asam folat namun berasal dari sumber nabati.

Hal ini didukung oleh penelitian Utomo, dkk. tahun $2015^{\left({ }^{9}\right)}$ yang menunjukkan bahwa asupan zat gizi terutama zat besi dan kepatuhan ibu hamil mengonsumsi tablet besi masih menjadi penyebab anemia pada ibu hamil. Ibu yang memperoleh asupan pangan sumber zat besi akan terhindar dari anemia, begitupula yang patuh mengkonsumsi tablet fe. Kenaikan volume darah selama kehamilan akan meningkatkan kebutuhan Fe atau Zat Besi. Jumlah Fe pada bayi baru lahir kira-kira $300 \mathrm{mg}$ dan jumlah yang diperlukan ibu untuk mencegah anemia akibat meningkatnya volume darah adalah $500 \mathrm{mg}$. Selama kehamilan seorang ibu hamil menyimpan zat besi kurang lebih $1.000 \mathrm{mg}$ termasuk untuk keperluan janin, plasenta dan hemoglobin ibu sendiri. Kebutuhan zat besi ibu hamil sekitar $46 \mathrm{mg} / \mathrm{hari}$, yang bisa dipenuhi dari makanan yang dikonsumsi sehari-hari ditambah dengan suplemen zat besi ${ }^{(10)}$.

Pada hasil penelitian ini diperoleh bahwa Ibu hamil yang sering mengkonsumsi pangan sumber asam folat tidak mengalami anemia, hal ini sesuai dengan hasil penelitian Setyaningsih, dkk ${ }^{(11)}$ yang menunjukkan bahwa asupan bahan pangan tinggi energi dan zat besi, serta konsumsi zat besi dan asam folat secara bermakna dijumpai menurunkan risiko kejadian anemia pada ibu hamil. konsumsi besi folat secara statistik bermakna menurunkan risiko terjadinya anemia pada ibu hamil.

Oleh sebab itu, perlu dilakukan upaya penanggulangan dan pencegahan anemia ibu hamil dengan cara peningkatan keanekaragaman konsumsi bahan makanan sumber zat besi, kesadaran ibu hamil untuk mengonsumsi tablet besi, dan peran serta suami dalam mendorong ibu hamil mengonsumsi tablet besi, perlu dilakukan suatu upaya penanggulangan dan pencegahan anemia secara lintas sektoral dan lintas program. Hal ini dapat dilakukan melalui program perbaikan kualitas konsumsi pangan seperti penganekaragaman bahan makanan sumber zat besi, distribusi bahan makanan yang merata, pemberdayaan ekonomi keluarga dan meningkatkan peran petugas kesehatan dalam peningkatan kesadaran penyuluhan dan konseling gizi dan kesehatan kepada ibu hamil, anggota keluarga dan masyarakat ${ }^{(9)}$.

\section{SIMPULAN DAN SARAN}

Ada hubungan yang bermakna antara frekuensi konsumsi pangan sumber zat besi dan asam folat dengan kejadian anemia pada ibu hamil di Wilayah kerja Puskesmas Tawaeli. Maka diharapkan kepada petugas kesehatan yang berada di wilayah kerja Puskesmas Tawaeli kiranya selalu memberikan berbagai informasi penting terhadap ibu hamil yang berkaitan dengan pemilihan bahan makanan yang penting untuk di konsumsi pada saat hamil serta di upayakan agar setiap posyandu memberikan penyuluhan kepada ibu hamil dan semoga penelitian ini bisa menjadi dasar penelitian bagi peneliti lain yang ingin meneliti lebih lanjut dengan metode yang berbeda sehingga bisa diketahui penyebab lain yang menyebabkan terjadinya anemia pada ibu hamil. 


\section{UCAPAN TERIMA KASIH}

Ucapan terima kasih kepada keluarga saya, teruntuk bapak dan ibu saya tercinta, bapak Agus dan Ibu Nirfan, serta adik saya tersayang Moh. Figar. Pada kesempatan ini tak lupa pula penulis mengucapkan terima kasih banyak kepada 1) Nasrul, SKM. M.Kes. selaku Direktur Poltekkes Kemenkes Palu atas izin pelaksanaan penelitian ini, 2) Sumiaty, SST. MPH. dan Ansar, SKM. M.Kes. selaku pembimbing yang sangat berperan aktif dalam proses pelaksanaan penelitian ini, 3) Kepala Puskesmas Tawaeli beserta staf Gizi yang telah membantu proses pengumpulan data penelitian dan 4) Seluruh Ibu hamil yang telah menjadi responden pada penelitian ini.

\section{DAFTAR PUSTAKA}

1. Ojofeitimi, EO, Ogunjuyigbe, PO dan Sanusi, dkk. 2008. Poor Dietary Intake of Energy and Retinol among Pregnant Women: Implications for Pregnancy Outcome., Southwest Nigeria : Pak J.Nutr, Vol. 7. 480-484.

2. MOST, USAID. 2004. A Strategic Apporoach to Anemia Control Program. Arlington Virginia USA : Micronutrient Program,.

3. Kemenkes, RI. Riset Kesehatan Dasar (Riskesdas). Jakarta : Balitbangkes Kemenkes RI, 2013.

4. Palu, Dinkes Kota. 2016. Profil Kesehatan Kota Palu. Palu : Dinkes Kota Palu,.

5. Sumiaty, Udin dan Aminuddin 2017. Anemia Kehamilan dan Jarak Persalinan dengan kejadian Perdarahan Postpartum di RSUD Undata Palu Propinsi Sulawesi Tengah.. 4, Palu : Jurnal Husada Mahakam, , Vol. IV. 315-325.

6. Jumarlina. 2007. Gambaran Faktor Penyebab Rendahnya Cakupan Fe3 pada Ibu Hamil di Puskesmas Maniangpajo Kab. Wajo. Makassar : Universitas Hasanuddin,.

7. Wulandari, Ika Novi. 2010. Hubungan antara konsumsi makanan sumber zat besi, enhancer, dan inhibitor, serta kepatuhan mengkonsumsi tablet tambah darah dengan kejadian anemia pada ibu hamil trimester III di Wilayah Kerja Puskesmas Panti Kabupaten Jember. Jember: Skripsi tidak diterbitkan.

8. Anggraini, Marissa. 2013. Hubungan Pola Konsumsi Pangan Dengan Kadar Hemoglobin Pada Ibu Hamil Trimester Ketiga Di Wilayah Kerja Puskesmas Desa Lalang Kecamatan Medan Sunggal. Medan : Skripsi tidak diterbitkan,.

9. Utomo, APW, Nurdiati, DS dan Padmawati, RS. 2015. Rendahnya Asupan Zat Besi dan Kepatuhan Mengkonsumsi tablet Besi Berhubungan dengan kejadian Anemia pada Ibu Hamil di Wilayah Kerja Puskesmas I Kembaran Banyumas. Jurnal Gizi dan Dietetik Indonesia, Vol. 3. 41-50.

10. Sulistyoningsih H,. 2011. Gizi untuk Kesehatan Ibu Dan Anak. Yogyakarta: Graha Ilmu,. 128.

11. Setyaningsih, W, Ani, LS dan Utami, NWA. 2015. Konsumsi Besi Folat, Tingkat

14 | Penerbit: Jurusan Kebidanan, Poltekkes Kemenkes Palu 
Kecukupan Energi dan Zat Besi Berhubungan dengan kejadian Anemia Ibu Hamil di Kabupaten Jember, Jember : Public Health and Preventive Medicine Archive, Vol. 3. 4-12. 